\title{
A standardized behavioral group treatment program for obsessive-compulsive disorder: preliminary outcomes
}

\author{
Kathleen P. Krone, Joseph A. Himle and RandolPh M. Nesse \\ Anxiety Disorders Program, Department of Psychiatry, University of Michigan, Med-Inn Building-Room \\ C438, 1500 E. Medical Center Drive, Ann Arbor, MI 48109.0840, U.S.A.
}

\author{
(Received 9 April 1991)
}

\begin{abstract}
Summary-This paper provides outcome data about the efficacy of a behavioral group therapy program for obsessive-compulsive disorder (OCD). Thirty-six patients completed a 7-week outpatient treatment program which provides: (1) education about OCD and its treatment, (2) instruction in a cognitive and behavioral approach to the self-treatment of OCD and (3) guided behavioral treatment. Significant improvement in obsession, compulsion, and depression scores were observed at completion of the group and at 3 month follow-up. Significant improvement in obsessions and compulsions was observed for both patients taking anti-obsessional medications and those who did not.
\end{abstract}

Despite the demonstrated effectiveness of individual behavioral treatment for obsessive-compulsive disorder (OCD) (Rachman \& Hodgson, 1980; Foa, Steketee, Doppelt, Turner \& Latimer, 1983; Foa, Steketee \& Ozarow, 1985), there have been no controlled studies of the effectiveness of group behavioral treatment for OCD. In contrast, the efficacy of group behavioral treatment for other anxiety disorders has been demonstrated (Emmelkamp \& Kuipers, 1985). Three reports have been published describing the behavioral group treatment of patients with obsessive-compulsive disorder (Hand \& Tichatzky, 1979; Marks, Hodgson \& Rachman, 1985; Epsie, 1986).

Hand and Tichatzky (1979) reported on 17 patients who participated in a three phase outpatient group program. Obsessive-compulsive disorder symptoms, problems in social interactions, and general problem solving skills were the targets of treatment. The promotion of group cohesion was considered to be an important variable in the treatment. During the initial phase ( 12 weeks), therapists held $2-3 \mathrm{hr}$ group sessions twice a week, conducted in vivo exposure sessions in the patient's home, and met with spouses apart from the group. During the second phase ( 6 weeks), patients began taking responsibility for the group treatment while the leaders 'faded out'. During the third phase (12 weeks), patients conducted goal-oriented self-help group sessions. Therapist time involved in these trials ranged from 122 to $147 \mathrm{hr}$. Outcome data from this uncontrolled study suggests some decrease in OCD symptoms as well as a decrease in anxiety.

Marks et al. (1985) offered an adjunctive group for patients who had completed their initial treatment of OCD symptoms. Patients and families met with a therapist every 4-6 weeks to discuss the impact of the patient's symptoms on the family, and to plan coping strategies. At times, patients would rehearse behavioral exercises in the group with the support of other members. Families found the group helpful, however, no outcome data were provided.

Epsie (1986) reported success with a 10 week group treatment for 5 OCD patients who had previously benefited from individual behavioral treatment and then relapsed. Patients attended weekly $90 \mathrm{~min}$ sessions to reactive skills previously learned during individual treatment. Each session focused on a particular topic and summary notes were provided. Homework log books were also utilized. Group members attended $60 \mathrm{~min}$ follow-up sessions at 6 weeks and 3 months. At the completion of the program, there was a significant decrease in ratings of obsessions and compulsions. These gains were maintained at $1 \mathrm{yr}$ follow up.

In order to further examine the efficacy of group behavioral therapy for obsessive-compulsive disorder, a group treatment program for OCD was developed and evaluated at the University of Michigan Anxiety Disorders Program. This paper describes the program and reports preliminary outcome data.

\section{METHODS}

Subjects

Forty patients were studied, 36 completed the group and 4 dropped out $(10 \%)$. All were outpatients who received a primary DSM-III-R diagnosis of Obsessive-Compulsive Disorder (American Psychiatric Association, 1987). All evaluations were performed by a clinician experienced in the diagnosis and treatment of obsessive-compulsive disorder and reviewed by a faculty psychiatrist. Evaluations involved (1) one or more face-to-face interviews, (2) questionnaires completed by the patient which are designed to provide information relevant to anxiety disorders, affective disorders, psychosis, and a variety of other psychiatric symptoms; and (3) information from other sources such as past records. The only patients excluded from the group were those with co-existing organic mental disorders, schizophrenia, or active substance abuse in the last 6 months.

Patients were at various stages of treatment at the beginning of the group program. Fourteen $(39 \%)$ were just starting treatment, while $22(61 \%)$ were already involved in pharmacological, behavioral, or psychological treatment. Concurrent treatments were minimized during participation in the program. No patients started on medication during the group, however, $16(55 \%)$ of the participants were already taking either clomipramine or fluoxetine at the time they started the

*Author for correspondence. 
Table 1. Comorbid diagnoses

\begin{tabular}{lccccccc}
\hline & $\begin{array}{c}\text { Major } \\
\text { depressive } \\
\text { disorder }\end{array}$ & Dysthymia & $\begin{array}{c}\text { Alcohol } \\
\text { dependence }\end{array}$ & $\begin{array}{c}\text { Anorexia/bulimia } \\
\text { nervosa }\end{array}$ & $\begin{array}{c}\text { Simple } \\
\text { phobia }\end{array}$ & $\begin{array}{c}\text { Social } \\
\text { phobia }\end{array}$ & $\begin{array}{c}\text { Panic } \\
\text { disorder/agoraphobia }\end{array}$ \\
\hline Current & 8 & 3 & 0 & 0 & 1 & 1 & 1 \\
Lifetime & 11 & 0 & 3 & 2 & 0 & 0 & 0 \\
\hline
\end{tabular}

group. One participant received individual behaviour therapy (unknown to the group therapists) during the course of the group. Five $(17 \%)$ were engaged in psychotherapy outside of the clinic at the time of the group.

The mean age of participants was $38 \mathrm{yr}$. Twenty-two were married or co-hahitating; 13 were single; and 1 was separated Twenty-two patients had at least one college degree; 13 had a high school education; and 1 had not completed high school. Ten of the patients were employed full-time; 5 were employed part-time; 1 was retired; 10 were homemakers; 3 were students; and 7 were unemployed or disabled. The mean duration of OCD symptoms for group members was $19 \mathrm{yr}$. Seventeen patients had at least one other comorbid diagnosis (Table 1).

Group treatment

The Obsessive-Compulsive Disorder Treatment Group is a 7-week closed-ended treatment program that provides: (1) education about OCD and its treatment, (2) instruction in a cognitive and behavioral approach to the self-treatment of $O C D$, and (3) guided behavioral treatment. The group meets once a week for $2 \mathrm{hr}$. The first hour provides education about OCD and it's treatment and the second hour offers behavioral treatment planning. This process is guided by experienced behavior therapists. During this clinical trial, a consistent co-therapy team (Kathleen Krore \& Joseph Himle) was utilized. Workbooks are provided which have information about OCD, space for taking notes and forms to document daily compliance and progress in behavior therapy.

Each week a new topic is covered in the educational component of the program. Adequate time is allowed for patients to share experiences and discussion is encouraged. Topics covered are: (1) the nature of OCD, (2) principles of behavior therapy, (3) causes of $O C D,(4)$ family life and $O C D$, (5) specialized techniques for making behavior therapy more effective, and (6) lifestyle and OCD. The seventh session is a summary in which patients raise topics for discussion and evaluate the treatment. In addition to the seven sessions, patients and families are invited to an optional family night. During this 2 -hr evening session, family members learn about $\mathrm{OCD}$ and its treatment. They also discuss family problems which arise as a result of the patient's OCD and how these might be handled.

During the behavioral treatment hour of the weekly group, patients apply the principles of exposure and response prevention to design an individualized self-treatment program. The first session is spent guiding patients in an individualized behavioral analysis. Once this is completed, goals for behavioral treatment are developed. Public goal setting appears to be an important component in this program, and patients encourage each other to meet their goals. In initial sessions, the therapists actively suggest exercises for patients to carry out between sessions. Brief in vivo exposure is conducted within the group, if necessary, to get patients started. By the end of the group, patients design their own behavioral exercises with the assistance of the therapists. The therapists cxplicitly adopt the role of coaches who help paticnts modify and refine their exercises and goals. Patients are expected to complete and record daily homework assignments.

During the first week of exercises, a phone contact is scheduled to answer questions and check on progress. After this, patients are encouraged to call if they were not able to comply with their exercises after the first few days of a given week. Exercises are then modified to enable them to have a successful week. After the first week, phone calls are infrequent.

Upon completion of the group, patients have the option of continuing individual behavioral therapy with their original therapists. For patients who are not on medication, a re-evaluation is done to determine if they might benefit further from medication. Patients on medication are evaluated to determine if a taper is indicated.

\section{MEASURES}

Obsessive-compulsive and depressive symptoms were rated pre-group (baseline), post-group, and at 3 month follow-up using the Yale-Brown Obsessive Compulsive Inventory (Y-BOCS) (Goodman, Price, Rasmussen, Mazure, Delgado, Heninger \& Charney, 1989a; Goodman, Price, Rasmussen, Mazure, Fleischmann, Hill, Heninger \& Charney, 1989b), and the Beck Depression Inventory (BDI) (Shaw, Vallis \& McCabe, 1985). The Y-BOCS measures the severity of OCD symptoms. This clinician-rated scale scores the severity of 10 items from 0 (None) to 4 (Extreme). The 10 items are divided into two subscales measuring obsessions and compulsions. This instrument has excellent inter-rater reliability and a high degree of internal consistency (Goodman et al, 1989b). It is also reported to be a valid tool which is sensitive to clinical changes (Goodman et al., 1989a). Y-BOCS ratings were done by one of the two group therapists.

The Beck Depression Inventory is a widely used self-report instrument for assessing severity of depression. There are 21 items that are scored between $0-3$. A score of $0-9$ is considered normal; 10-15, mild depression; 16-23, moderate depression; and 24-63, severe depression. Concurrent validity of the BDI is in the range of $0.62-0.77$ (Shaw et al., 1985).

\section{RESULTS}

Data were analyzed for 3 groups: all group completers $(n=36)$, patients on medication during the group $(n=19)$, and patients who took no medication during the group $(n=17)$. Patients on medication and those that were medication free during the group did not differ significantly in sex, marital status, level of education, employment status, age, duration of symptoms or Y-BOCS score at the start of the group. Patients on medication had significantly higher mean BDI scores (18.8 vs $11.7, F=6.38, P<0.017)$.

A one factor ANOVA of repeated measures for the 36 completers showed a significant decrease in the total Y-BOCS scores from 21.2 at baseline to 16.11 at the end of the group $(F=34.99$, d.f. $=34, P<0.0001)$ (Table 2$)$. The Y-BOCS obsession subscale decrcased from 10.5 to $7.9(F=23.62$, d.f. $=34, P<0.0001)$ and the compulsion subscale decreased from 10.6 to $8.3(F=21.05$, d.f. $=34, P<0.0001)$. During this same period the mean BDI scores decreased from 15.6 to 11.1 $(F=7.78$, d.f. $=30, P<0.0091)$ (Table 3$)$. Although baseline BDI scores were not significantly correlated with improvement in Y-BOCS scores, improvement in BDI scores were significantly correlated with Y-BOCS improvement scores $(F=10.25$, d.f. $=29, P<0.003)$. 
Table 2. Mean Yale-Brown scores

\begin{tabular}{|c|c|c|c|c|c|c|c|c|c|c|c|c|}
\hline & \multicolumn{2}{|c|}{ Baseline } & \multicolumn{2}{|c|}{ End of group } & \multirow[b]{2}{*}{$F$} & \multirow[b]{2}{*}{ d.f. } & \multirow[b]{2}{*}{$P$} & \multicolumn{2}{|c|}{3 month follow-up } & \multirow[b]{2}{*}{$F$} & \multirow[b]{2}{*}{ d.f. } & \multirow[b]{2}{*}{$P$} \\
\hline & Mean & $\mathrm{SD}$ & Mean & $\mathrm{SD}$ & & & & Mean & SD & & & \\
\hline $\begin{array}{l}\text { All } S \mathrm{~s} \\
\quad n=35\end{array}$ & 21.2 & 6.45 & 16.1 & 6.5 & 34.99 & 34 & 0.0001 & 11.6 & 6.38 & 17.9 & 24 & $0.0003+$ \\
\hline $\begin{array}{l}\text { No medication } \\
\quad n=17\end{array}$ & 20.4 & 6.34 & 17.2 & 6.94 & 7.44 & 16 & 0.015 & & $*$ & & & \\
\hline $\begin{array}{c}\text { Medication } \\
n=18\end{array}$ & 219 & 6.64 & 15.1 & 6.09 & 37.18 & 17 & 0.0001 & & $*$ & & & \\
\hline
\end{tabular}

*Treatment conditions not held constant.

tEnd of group to 3 month follow-up $(n=24)$.

Table 3. Mean Beck Depression Inventory scores

\begin{tabular}{|c|c|c|c|c|c|c|c|c|c|c|c|c|}
\hline & \multicolumn{2}{|c|}{ Baseline } & \multicolumn{2}{|c|}{ End of group } & \multirow[b]{2}{*}{$F$} & \multirow[b]{2}{*}{ d.f. } & \multirow[b]{2}{*}{$P$} & \multicolumn{2}{|c|}{3 month follow-up } & \multirow[b]{2}{*}{$F$} & \multirow[b]{2}{*}{ d.f. } & \multirow[b]{2}{*}{$P$} \\
\hline & Mean & $\mathrm{SD}$ & Mean & SD & & & & Mean & $\mathrm{SD}$ & & & \\
\hline $\begin{array}{l}\text { All } S \mathrm{~s} \\
\quad n=31\end{array}$ & 15.6 & 8.99 & 11.1 & 9.04 & 7.78 & 30 & 0.0091 & 7.9 & 7.49 & 10.0 & 23 & $0.004 t$ \\
\hline $\begin{array}{l}\text { No medication } \\
n=14\end{array}$ & 11.7 & 8.11 & 12.0 & 11.88 & & NS & & * & & & & \\
\hline $\begin{array}{l}\text { Medication } \\
\qquad n=17\end{array}$ & 18.8 & 8.62 & 10.4 & 6.11 & 15.03 & 16 & 0.0013 & $*$ & & & & \\
\hline
\end{tabular}

- Treatment conditions not held constant.

$\dagger$ End of group to 3 month follow-up $(n=24)$.

Both scores continued to improve after completion of the formal group program, with an additional Y-BOCS change from 15.7 to $11.6(F=17.9$, d.f. $=24, P<0.0003)$ and BDI change from 10.7 to $7.9(F=10.0$, d.f. $=23, P<0.004)$ at the 3 month follow-up visit. Treatment during this follow-up period was not standardized between patients so few conclusions can be drawn as to variables which accounted for continued improvement in Y-BOCS and BDI scores. However, when mean Y-BOCS scores for patients in the eight possible follow-up conditions were examined separately, there was a trend toward continued improvement in all conditions. This trend toward improvement continued for both patients in active pharmacological or behavioral treatment $(n=20)$ and those not involved in active treatment $(n=5)$.

The same analyses were conducted for the subgroups of patients who did and did not use medication during the group treatment program. Those patients on medication had a significant change in total Y-BOCS scores from 21.9 to 15.1 $(F=37.18$, d.f. $=17, P<0.0001)$, with an obsession subscale change from 10.9 to $7.5(F=23.5$, d.f. $=17, P<0.0002)$ and compulsion subscale change from 10.8 to $7.8(F=22.2$, d.f. $=17, P<0.0002)$. Mean BDI scores for the medication group decreased from 18.8 to $10.4(F=15.03$, d.f. $=16, P<0.0013)$. Patients not on medication also had a significant change on their total Y-BOCS scores from 20.4 to $17.2(F=7.44$, d.f. $=16, P<0.015)$ and obsession subscale score from 10.0 to $8.2(F=5.01$, d.f. $=16, P<0.04)$. Change in the compulsion subscale score approached significance $(F=4.09$, d.f. $=16$, $P<0.06)$. No significant change in BDI scores were found among the non-medication group.

\section{DISCUSSION}

This preliminary study suggests that short-term group behavioral treatment can be an efficient and effective form of treatment for obsessive-compulsive disorder. The group of 36 patients who completed the program showed a significant decrease in their obsessive-compulsive symptoms whether or not they were taking medication during the course of the group. These findings are unlikely to result from placebo effects in light of the minimal changes in OCD symptoms in a large group of patients treated with placebo (De Veaugh-Geiss, Landau \& Katz, 1989). The findings are also consistent with other preliminary reports of the effectiveness of group treatment for OCD (Hand \& Tichatzky, 1979; Epsie, 1986). This group, however, differs from the group reported by Hand and Tichatzky in that all behavior therapy during the study period was provided within the group format. In addition, the group differs from Epsie's group as his group consisted of only patients who had relapsed after successful individual behavior therapy.

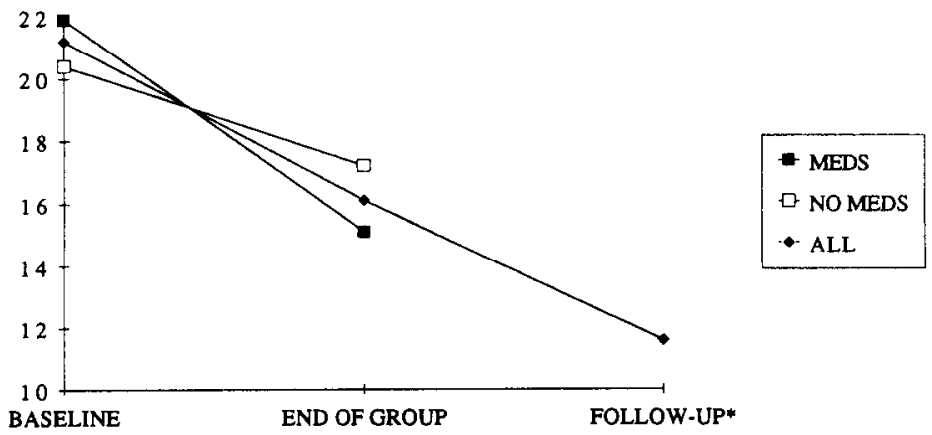

Fig. 1. Mean Yale-Brown scores. 


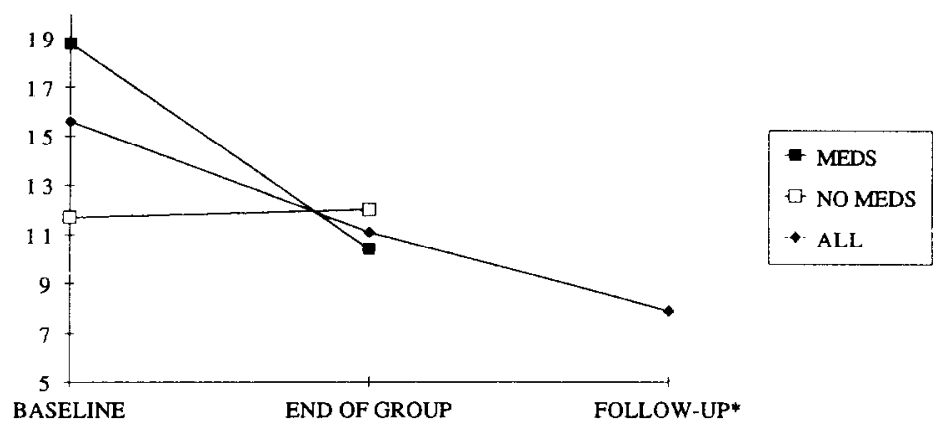

Fig. 2. Mean Beck Depression Inventory scores.

The present study also demonstrated that patients continued to improve after completing the formalized group program. However. treatment during this period was not standardized, so few conclusions can be drawn about variables that contributed to this continued improvement. Some patients continued individual behavioral treatment, some added or deleted medication from their treatment programs, and some stopped all formal treatment at the conclusion of the group.

Patients who participated in the group also experienced a significant reduction in depressive symptomatology. Improvement in BDI and improvement in Y-BOCS scores were found to be significantly correlated. These correlations remained positive when the medication and non-medication groups were examined independently.

This preliminary study was designed mainly to obtain pilot data on the standardized group treatment program in preparation for a controlled study, so patients were not randomly assigned to treatment conditions. Controlled studies are needed to further demonstrate the efficacy of short-term behavioral group treatment for patients with obsessive-compulsive disorder. The outcomes of this treatment model must be compared with other effective treatments such as individual behavior therapy (Rachman \& Hodgson, 1980, Foa et al., 1983, 1985) and medication (Pato, Zohar-Kadouch, Zohar \& Murphy, 1988; Jenike, 1990; Pigott, Pato, Bernstein, Grover, Hill, Tolliver \& Murphy, 1990; Insel, 1990). Similarly, it would be useful to explore whether a combination of medication and group behavioral treatment has additional benefit over group treatment alone. It must be determined what effect such variables as severity of OCD and depressive symptoms have on group treatment outcomes. Further studies are also needed on long-term outcome.

Despite the limitations of this preliminary study, it demonstrates the promise of short-term behavioral group treatment as an effective and efficient treatment of obsessive-compulsive disorder. The program is standardized and easily implemented. It requires less therapist time than other behavioral programs. Most importantly, OCD symptoms are substantially reduced in a relatively short period of time.

\section{REFERENCES}

American Psychiatric Association (1987) Diagnostic and statistical manual of mental disorders (3rd edn, rev.). Washington, D.C.: American Psychiatric Association.

DeVeaugh-Geiss, J., Landau, P. \& Katz, R. (1989). Treatment of obsessive-compulsive disorder with clomipramine. Psychiatric Annales, 19, 97-101.

Emmelkamp, P. M. G. \& Kuipers, A. C. M. (1985) Behavioral Group Therapy for Anxiety Disorders. In Upper, D. R. (Ed.), Handbook of behavioural group therapy (pp. 443-469). New York: Plenum Press.

Epsie C. A. (1986). The group treatment of obsessive-compulsive ritualizers: Behavioral management of identified patterns of relapse. Behavioural Psychotherapy, 14, 21-33.

Foa, E. B., Steketee, G. S. \& Ozarow, B. J. (1985). Behavior therapy with obsessive-compulsives: From theory to treatment In Mavissakalian, M., Turner, S. M. \& Michelson, L. (Eds), Obsessive-compulsive disorders: Psychological and pharmacological treatment (pp. 49-121). New York: Plenum Press.

Foa, E. B., Steketee, G. S., Doppelt, H. G., Turner, S. M. \& Latimer, P. L. (1983). Success and failure in the behavioral treatment of obsessive-compulsives. Journal of Consulting and Clinical Psychology, 15, 287-297.

Goodman, W. K., Price, L. H., Rasmussen, S. A., Mazure, C., Delgado, P., Heninger, G. R. \& Charney, D. S. (1989a) The Yale-Brown Obsessive Compulsive Scale: II. Validity. Archives of General Psychiatry, 46, 1012-1016.

Goodman, W. K., Price, L. H., Rasmussen, S. A., Mazure, C., Fleischmann, R. L., Hill, C. L., Heninger, G. R. \& Charney, D. S. (1989b). The Yale-Brown Obsessive Compulsive Scale: I. Development, use, and reliability. Archives of General Psychiatry, 46, 1006-1011.

Hand, I. \& Tichat7ky, M. (1979) Behavioral group therapy for obsessions and compulsions: First results of a pilot study In Sjoden, P. O. Bates, D. \& Dockens, W. S. (Eds), Trends in behavior therapy (pp. 269-297). New York: Academic Press.

Insel, T. R. (1990). New pharmacologic approaches to obsessive compulsive disorder. Journal of Clinical Psychiatry, $5 l$, $47-51$.

Jenike, M. A. (1990). Drug treatment of obsessive-compulsive disorder. In Janike, M. A., Baer, L. \& Minichiello, W. E. (Eds), Obsessive-compulsive disorders: Theory and management (2nd edn), (pp. 249-282). Chicago: Year Book Medical Publishers.

Marks, I. M., Hodgson, R. \& Rachman, S. (1975). Treatment of chronic obsessive, compulsive neurosis by in vivo exposure. British Journal of Psychiatry 127, 349-364.

Pato, M. T., Zohar-Kadouch, R., Zohar, J. \& Murphy, D. L. (1988). Return of symptoms after discontinuation of clomipramine in patients with obsessive-compulsive disorder. American Journal of Psychiatry, 145, 1521-1525. 
Pigott, T. A., Pato, M. T., Bernstein, W. E., Grover, G. N., Hill, J. L., Tolliver, T. J. \& Murphy, D. L. (1990). Controlled comparisons of clomipramine and fluoxetine in the treatment of obsessive compulsive disorder: Behavioral and biological results. Archives of General Psychiatry, 47, 926-932.

Rachman, S. J. \& Hodgson, R. S. (1980) Obsessions and compulsions. Englewood Cliffs, N.J.: Prentice-Hall.

Shaw, B. F., Vallis, T. M. \& McCabe, S. (1985). The assessment of the severity and symptom patterns in depression. In Beckham, E. E. \& Leber, W. R. (Eds), Handbook of depression: Treatment, assessment, and research (pp. 372-406). Illinois: Dorsey Press. 